\title{
Contribuições da Escola Italiana de História das Religiões
}

\author{
Contributions from the Italian School of History of Religions
}

João Miguel Teixeira Godoy*

Fernando César Butignol**

\begin{abstract}
Resumo
A Escola Italiana tem influenciado de forma crescente não só a historiografia brasileira no campo dos estudos religiosos, como também auxiliado na consolidação da emergente área das Ciências das Religiões, com seu refinamento conceitual e metodológico de análise, que estimula problematizar a singularidade do objeto religioso, ao precisar seus conceitos e métodos de reconstrução.
\end{abstract}

Palavras-chave

História das Religiões. Escola Italiana. Pettazzoni.

\begin{abstract}
The Italian School has influenced increasingly not only the Brazilian historiography in the field of religious studies, as well as assisted in the consolidation of the emerging field of Sciences of Religions, with their conceptual and methodological refinement analysis, which stimulates questioning the uniqueness of the object religious, by specifying its concepts and methods of reconstruction.
\end{abstract}

\section{Keywords}

History of Religions. Italian School. Pettazzoni.

\section{A Escola Italiana de História das Religiões: surgimento e principais expoentes}

De que forma a religião é analisada pela ciência histórica? Como este encontro problematiza e amplia o conceito de religião, alinhando-o às questões históricas modernas sobre laicização, secularização, alteridade e diversidade cultural e religiosa? $\mathrm{O}$ objetivo deste artigo é descrever, de forma introdutória e despretensiosa, a teoria e a metodologia desenvolvidas pela "Escola Italiana de História das Religiões" e sua receptividade nos

[Texto recebido em agosto de 2016 e aceito em janeiro de 2018, com base na avaliação cega por pares realizada por pareceristas ad hoc]

* Docente do Programa de Pós-Graduação em Ciências da Religião (PUC-Campinas). Docente da Faculdade de História (PUC-Campinas). Doutor em História Econômica (USP). E-mail: joaomigueltgo@yahoo.com.br

** Graduado e Especialista em Odontologia (USP). Bacharelando em História (PUC-Campinas). E-mail: fernando.cb@puc-campinas.edu.br 
meios acadêmicos brasileiros, contribuindo, assim, com possibilidades de escolha de interpretação para os estudos histórico-religiosos brasileiros - nos quais nem sempre estão bem definidos os métodos empregados - e para o amadurecimento da disciplina de História das Religiões, ainda em desenvolvimento no Brasil.

A “Escola Italiana de História das Religiões" tem suas primeiras sementes plantadas por volta de 1920, pelo historiador Rafaelle Pettazzoni (1883-1959). Em 1924, ele inaugura a primeira cátedra da disciplina na Universidade de Roma e a revista Studi $e$ Materiali di Storia delle Religioni, que surge em 1925, é a melhor expressão de sua perspectiva de estudos. Nessa época, a Itália havia passado por uma forte crise social e econômica com a Primeira Guerra Mundial. A depressão pós-guerra veio acompanhada do descrédito no sistema liberal e do aparecimento de organizações socialistas e comunistas, num crescente conflito de classes e de interesses. Em 1920, milhares de trabalhadores e camponeses italianos reivindicavam seus direitos, havia pouco consenso entre os partidos políticos e o fascismo se consolidava. $\mathrm{O}$ modelo civilizatório europeu havia falido, trazendo uma série de questionamentos de ordem econômica, política, social e cultural. Em Roma, o contexto dos estudos religiosos era dominado pelo filósofo napolitano Benedetto Croce e pelos estudos bíblicos e eclesiásticos da Igreja Católica. Um ambiente pouco favorável para uma análise histórica racional e plural do fenômeno religioso. Pettazzoni, no entanto, busca romper com tal hegemonia interpretativa eurocêntrica de filósofos, antropólogos e teólogos, furtando-se ao método da compilação manualística descritiva de crenças religiosas e propondo a necessidade de historicizar a experiência religiosa. De acordo com Agnolin,

Neste momento de amadurecimento da gênese da escola italiana, são finalmente afinadas as coordenadas destinadas a orientar os estudos histórico-religiosos, partindo da necessidade de ressaltar, antes de mais nada, a historicidade dos fatos religiosos enquanto produtos culturais, redutíveis em sua totalidade à razão histórica. [...] Desde seu nascimento, a "Escola Italiana de História das Religiões" encontrou-se instalada, epistemológica e historicamente, no entrelaçamento entre as disciplinas da Antropologia e da História, tendo que encarar, consequentemente, a polêmica aberta e crítica com a Filologia, com a Fenomenologia e com todas as outras disciplinas e escolas de pensamento que, eventualmente, confundindo-se com a História das Religiões, privilegiavam abordagens anistóricas, quando não, pior, desistoricizantes. ${ }^{1}$

Pettazzoni problematiza o conceito de religião a partir de uma revisão crítica do evolucionismo de Edward B. Tyler e Herbert Spencer, da abordagem sociológica de Durkheim e Mauss e da fenomenologia de Rudolf Otto e Van der Leeuw, descrita em seu artigo La formazione del monoteismo - il problema de Dio, de 1949, no qual desconstrói os "mitos científicos" dos principais cânones das escolas teológicas, etnológicas e

1 AGNOLIN, A. História das Religiões: perspectiva histórico-comparativa. São Paulo: Paulinas, 2013. p. 67-68. 
antropológicas, cuja ressignificação dará as bases para a metodologia da escola italiana. A composição do seu trabalho intelectual se desenvolveu pela experimentação, criando um conceito plural de religião, no qual a diversidade de sistemas religiosos reconhece não só um mesmo grau de dignidade entre eles, como também uma pluralidade de histórias. Para Pettazzoni, "toda religião é um produto histórico, culturalmente condicionado pelo contexto e, por sua vez, capaz de condicionar o próprio contexto em que opera" ${ }^{2}$ Privilegiando o método comparativo-histórico e sua incompatibilidade com a visão teológica, como descrito na obra Il metodo comparativo, de 1959, ele coloca no centro de sua reflexão a relação entre sagrado e profano. As bases sólidas e o desenho historiográfico criados por Pettazzoni se fortaleceram e amadureceram com a contribuição de importantes autores como Ernesto De Martino, Angelo Brelich, Vittorio Lanternari, Dario Sabbatucci, Marcelo Massenzio, Gilberto Mazzoleni, Paolo Scarpi e Nicola Gasbarro, entre outros.

O historiador e etnólogo Ernesto De Martino (1908-1965) foi um importante colaborador para o refinamento teórico-metodológico da escola romana. Mesmo não tendo feito parte da linhagem sucessória do movimento ou pertencido ao círculo de discípulos de Pettazzoni, ele foi considerado uma segunda referência na construção de uma chave de interpretação dos fenômenos religiosos e teve seu trabalho imediatamente reconhecido pelos herdeiros de Pettazzoni. Ele teve uma forte influência de Benedetto Croce, discordando deste ao considerar os povos e massas subalternas como atores da História. Foi receptivo às ideias psicanalíticas, do existencialismo e do marxismo e fez fortes ataques ao irracionalismo fenomenológico. A teoria hierogenética (sobre a construção cultural do sagrado) dirigiu seus importantes estudos sobre a religião popular. Concebeu ensaios antinaturalistas e a historicização da etnologia e do folclore, além da crítica à marginalização histórica das sociedades primitivas e da "plebe" do Ocidente. Seus textos mais famosos são Il mondo magico (1948), Morte e Pianto Rituale (1958), Sud e Magia (1959), La Terra del Rimorso (1961) e Furore, Simbolo, Valore (1962).

Angelo Brelich (1913-1977), sucessor de Raffaele Pettazzoni na cátedra romana em 1959, foi um grande estudioso do mundo clássico, para quem a definição de "religião" supunha o (re)conhecimento da pluralidade das religiões, um conceito historicamente construído que critica e desconstrói a visão ocidental hegemônica e ímpar de analisar o objeto religioso. Em sua obra Prolégomèns à une Historie dês Religions, ${ }^{3}$ o autor trabalha engenhosamente numa definição ampla de religião e reflete sobre a disciplina de História das religiões enquanto a portadora do fundamento teórico que legitima o método. Brelich trabalha com a comparação intercultural: um estudo das crenças como chave teórica para

2 MASSENZIO, M. A história das religiões na cultura moderna. São Paulo: Hedra, 2005. p. 149.

3 Prolegomeni a una Storia delle Religioni. In: PUECH, E. C. (Org.). Storia delle Religioni. Bari: Laterza, 1970; ed. francesa: Prolégomènes pour l'Histoire des Religions. In: Encyclopédie de la Plêiade. Paris: Gallimard, 1970-1976; ed. espanhola: Prolegomenos de una Historia de las Religiones. In: Historia de Las Religiones. Las Religiones antigas I. Madrid: Siglo XXI, 1997. p. 30-97. Agora In: BRELICH, Angelo. Storia delle Religioni: perché? Napoli: Liguori Editore, 1979. 
entender a religião dentro de uma pluralidade de culturas, reforçando a necessidade de se trabalhar com a diversidade cultural, no âmbito da Nova História Cultural. Seus trabalhos tiveram um caráter historicista e anti-irracionalista, ao mesmo tempo que enriqueceram o método comparativo com abordagens antropológicas. Outras obras que merecem destaque são Gli Eroi Greci: un problema historico-religioso, de 1978, Il politeismo (1958) e Introduzione alla Storia delle Religioni, de 1965. Como Pettazzoni, ele foi um forte combatente dos "essencialistas", portadores de um modelo a-histórico totalizante capaz de conter a multiplicidade dos sistemas religiosos, tirando deles o seu caráter de "processos".

Vittorio Lanternari (1918-2010) foi também um importantíssimo expoente da escola romana. Seguidor da metodologia comparativa da escola pettazzoniana, influenciado pelas ideias demartinianas, leitor de Gramsci e da antropologia social inglesa, ele define a religião evitando a irracionalidade e dispondo de uma "peculiar perspectiva historiográfica marxista". Sua tendência de pesquisa era de percorrer itinerários explicativos do fato religioso, com uma metodologia que flerta com as rebeliões religiosas estruturadas em torno de módulos profético-messiânicos, utilizando uma antropologia religiosa focada nos fenômenos religiosos e culturais de fronteira, em áreas de pressão colonialistas e de fortes transformações culturais e ideológicas geradoras de sincretismos religiosos, produtos de aculturação e reaculturação, atém de investigar o encontro/desencontro histórico-cultural e histórico-religioso entre Ocidente e Terceiro Mundo. Em sua obra Religiões dos oprimidos: um estudo dos modernos cultos messiânicos (1974), um dos poucos textos da Escola Italiana que foi traduzido para o português, Lanternari faz um "estudo das inter-relações dialéticas entre a vida religiosa e a vida profana". ${ }^{4}$ Além desta obra mais famosa, recomenda-se também a leitura de Occidente $e$ Terzo Mondo (1972), Antropologia e Imperialismo (1974) e Antropologia religiosa: etnologia, storia, folklore (1997).

Titular desde 1971 da segunda cátedra de História das Religiões da Universidade La Sapienza de Roma, Dario Sabbatucci (1923-2004) foi citado por outro partidário da escola italiana como "quem, talvez melhor que os outros, conseguiu filtrar e atualizar com suas vivazes intuições a complexa herança de Pettazzoni, De Martino e Brelich". Pesquisador do mundo clássico e de grande erudição, ele estudou o fenômeno místico a partir de um perspectiva histórico-religiosa na obra Ensaios sobre o misticismo grego (Saggio sul Misticismo Greco, 1965), a especificidade da religiosidade romana e grega com Lo Stato come Conquista Culturale: Ricerca sulla Religione Romana (1975) e Il Mito, il Rito e la Storia (1978), aprimorando os conceitos de mito/rito e monoteísmo/politeísmo.

Marcello Massenzio é o atual titular da cátedra de História das Religiões da Faculdade de Letras e Filosofia “Tor Vergata” em Roma e especialista no mundo clássico. Em seu livro traduzido para o português, A História das Religiões na cultura moderna (2005),

4 LANTERNARI, V. As religiões dos oprimidos. São Paulo: Perspectiva, 1974. 
o autor busca por meio da associação entre história das religiões com a antropologia religiosa, definir o objeto religioso na tradição da escola italiana, dando-lhe um sentido híbrido e plural, assumindo sua diversidade cultural, a partir da crítica à interpretação do fato religioso por antropólogos e teólogos do séc. XIX e início do séc. XX. Dessa forma, ele questiona não só os instrumentos de análise do fato religioso do mundo ocidental, rejeitando os preconceitos eurocêntricos e criticando o patrimônio cultural ocidental, à luz da alteridade cultural, mas também os conceitos básicos da religião, problematizando as vertentes sistemática e fenomenológica. Para isso, ele utiliza as obras cânones da antropologia, teologia e história. $\mathrm{O}$ autor busca desconstruir a chave de interpretação evolucionista e essencialista, a fim de justificar a importância da historicidade do fato religioso e de sua pluralidade, bases da Escola Romana de História das Religiões.

Como Sabbatucci, seu sucessor de cátedra Gilberto Mazzoleni é discípulo de Brelich. O foco do seu trabalho são os povos e culturas do Norte da Europa e Américas, buscando "detectar um processo de historicização das ideias que a cultura ocidental expressou reencontrando ou inventando o diferente de $\mathrm{si}^{\prime \prime} .{ }^{5} \mathrm{O}$ impacto entre Ocidente e culturas tradicionais trouxe inúmeros mal-entendidos nas análises sobre outros povos e culturas e consequências sérias que construíram ideias falsas que precisam ser revistas a partir de um "etnocentrismo crítico", reflexão esta já iniciada com E. De Martino. Para essas "armadilhas" encontradas na perspectiva etnocêntrica, Mazzoleni sugere a efetivação de uma "Antropologia histórica", uma metodologia histórico-religiosa aliada a intensos trabalhos de campo que rendeu a obra traduzida para o português O planeta cultural: para uma Antropologia histórica, de 1992, dentre outros trabalhos.

Professor de História das Religiões na Universidade de Pádua e especialista em estudos clássicos, Paolo Scarpi é uma referência elogiável no desenvolvimento da Escola Italiana ao prezar, nos seus estudos sobre o mundo grego, a relação entre funções míticorituais e as esferas econômica e social, indicadas por Pettazzoni e Brelich. Assim como fez Sabbatucci, suas pesquisas dialogavam com a chamada "Escola de Paris", num círculo de amizades no qual predominavam especialistas clássicos como Jean-Pierre Vernant, Pierre Vidal-Naquet e Marcel Detienne e onde ideias eram trocadas e criticadas e as especificidades esclarecidas e fortalecidas. A criação do título "Escola Romana de História das Religiões" serve para definir, em contraposição à "Escola De Paris", a sua especificidade teórica e metodológica:

Dentro da perspectiva histórico-religiosa da vertente italiana, desenvolveuse, portanto, um percurso histórico, próprio e específico, que viu essa tradição de estudos aprimorar metodologias e instrumentos de pesquisa. [...] Foi desenvolvendo um seu itinerário específico de indagação. E foi, justamente, a fim de evidenciar essa especificidade que, em 1973, na cidade

5 AGNOLIN, 2013, p. 132. 
de Urbino (Itália), foi cunhado o nome de “Escola Romana de História das Religiões" ${ }^{\prime}$

Para Scarpi e seus pares, "o modo de fazer a história da religião depende, em última instância, do modo segundo o qual a religião é concebida". Sua obra Politeísmos: as religiões do mundo antigo (2004) revela singularidades e homogeneidade nas religiões antigas, caracterizadas como étnicas e organizadas pela relação com seus muitos deuses. Outras duas importantes obras do autor são La fuga e il ritorno: teria e mitologia del viaggio (1992) e Si fa presto a tire Dio: riflessioni per um multiculturalismo religioso (2010).

Grande colaborador de Sabbatucci e Mazzoleni, Nicola Gasbarro é atualmente professor de História das Religiões em Roma, na Universidade La Sapienza. Seus estudos entrecruzam Antropologia, História das Religiões e História tout court. Orientando de Paolo Scarpi e herdeiro intelectual de Sabbatucci, seus trabalhos se preocupam com a comparação histórico-religiosa e antropológica e as relações entre as civilizações. Enquanto disciplina humanista, a História das Religiões analisa "com olhar distanciado" aquilo que foi escrito sobre outras culturas ao mesmo tempo que desenvolve uma autocrítica sobre a sua própria cultura; a busca por diferenças e a procura por sua compatibilidade prática. Praticante de uma metodologia fortemente historicista, a influência de Gasbarro no Brasil tem sido crescente com contribuições nas obras Nós e o Islã: uma compatibilidade possível? (2003), Missões: a civilização cristã em ação (2006) e Império Simbólico (2011).

\section{Influências da Escola Italiana no meio acadêmico brasileiro}

A produção acadêmica brasileira de conhecimento histórico sobre os fatos religiosos revela uma necessidade de alinhar produção cientifica e reflexão teóricometodológica. Nesse sentido, uma das metas desta pesquisa é buscar autores brasileiros que se apropriaram dos processos de pesquisa da "Escola Italiana de História das Religiões" como forma de delimitar o campo religioso e de instrumentalizar, orientar e refinar os estudos de seus objetos.

Maria Cristina Pompa (UNIFESP), Adone Agnolin (USP) e Paula Montero (CEBRAP/SP) são alguns exemplos desses profissionais que adotaram a perspectiva italiana em suas linhas de pesquisa que beneficiam, sobretudo, o contexto históricocolonial brasileiro. Com o trabalho Religião como tradução: missionários, Tupi e Tapuias no Brasil (2002), Pompa privilegia a vertente da "antropologia historicamente fundada" de Mazzoleni, que a auxilia no estudo da missão no contexto colonial brasileiro, embasando, assim, uma "antropologia histórica das missões" bastante específica. O historiador Agnolin, em Jesuítas e Selvagens: a negociação da fé no encontro catequético-ritual americano-tupi (séc. XVI-XVII), de 2007, dialoga com De Martino, Sabbatucci, Massenzio, Scarpi e

6 AGNOLIN, 2013, p. 67. 
Gasbarro para a eleição de uma matriz teórica que guiará a obra no sentido de repensar o papel dos índios enquanto agentes históricos. A antropóloga Paula Montero contribui organizando a coletânea Deus na aldeia: missionários, índios e mediação cultural, de 2006, um debate com a participação de diferentes profissionais, mediados por Nicola Gasbarro, cujas reflexões histórico-religiosas tentam recuperar a formação histórica e antropológica do encontro entre missionários e índios, auxiliando, desse modo, na compreensão do "outro".

O cientista da religião e historiador Elton de Oliveira Nunes, da Faculdade Messiânica, sugere em seu artigo, Teoria e Metodologia em História das Religiões no Brasil: o estado da arte (2011), que, em razão do Brasil ser um caldeirão de religiões e da própria disciplina histórica ainda resistir em descrevê-lo a partir de bases positivistas e marxistas, os estudos acadêmicos do campo religioso necessitam de uma melhor acuidade teóricometodológica, sendo favorável promover centros de diálogo sobre novas bases de estudo do fenômeno religioso, nos quais o espaço a Escola Italiana tem uma importante contribuição. Para ele, a História das Religiões no Brasil está pouco definida e tem desafios a enfrentar, como sua multidisciplinaridade, seu trabalho com o conceito controverso e abrangente de "religião" e a postura ainda tímida dos seus historiadores, além dos estudos brasileiros serem exclusivamente vinculados aos cursos de pós-graduação, grupos de pesquisa e instituições como a Associação Brasileira de História das Religiões (ABHR), ainda com linhas e correntes indefinidas e dificuldade de classificação dos estudos históricos sobre religião. $\mathrm{O}$ artigo de Nunes evidencia a busca dos historiadores das religiões por chaves de interpretação alternativas e formas de refinamento de modelos interpretativos para os estudos histórico-religiosos brasileiros e alguns deles têm mostrado empatia e afinidade pela "Escola Italiana de História das Religiões".

Um trabalho de Karina Bellotti, ${ }^{7}$ historiadora e pesquisadora da UFPR, indica a vigência dos modelos de formação positivista e marxista, exclusivamente europeus e norteamericanos, dos historiadores brasileiros (sobretudo os "USPianos"), que reduzem o sagrado a uma mera representação social e política, criando uma visão negativa da despersonalização do objeto e uma necessidade urgente de alargar o leque teóricometodológico sobre o estudo das religiões. Ela sugere não só a inclusão da História das Religiões na matriz curricular, como também a contemplação de espaços de discussão sobre diferentes teorias de abordagem, como a da "Escola Italiana de História das Religiões", que ainda apresenta poucos trabalhos difundidos e traduzidos no Brasil. Para a autora, no seu artigo História das Religiões: Conceitos e debates na era contemporânea (2011), o fenômeno religioso não se limita mais às instituições que o representam, mas, de acordo com a "Escola Italiana da História das Religiões", é um conjunto de crenças coletivas ou individuais, e práticas definidoras de identidade, relativas a seres sobre-humanos. Uma

7 BELLOTTI apud NUNES, Elton O. Teoria e Metodologia em História das Religiões no Brasil: o estado da arte. História: Questões E Debates, Curitiba, n. 55, p. 43-58, jul./ dez. 2011. 
pesquisa rica historiciza crenças e práticas, promove a ampliação de objetos, destitui as grandes narrativas e o seu sujeito eurocêntrico, questiona o conceito judaico-cristão de religião e busca diálogo com a antropologia e a sociologia para novas definições de cultura e identidade e sua incorporação no estudo das religiões.

O filósofo e historiador Fernando Torres Londoño, da PUC-SP, descreve em seu artigo História das Religiões (2013), algumas características da Escola Italiana e de seus expoentes. De acordo com o autor, Pettazzoni estuda as religiões inseridas na História, isto é, que se desenvolvem em situações históricas dadas, esclarecendo que o conceito de "religião" no singular nasce com o pensamento judaico-cristão, cujo monoteísmo inventa o termo "politeísmo", do qual se origina. Assim, ele o usa no plural e sugere um método comparativo que busca aspectos gerais e particulares das religiões em suas origens, continuidades e rupturas. Inspirada pelos estudos da Etnologia, questiona e reformula conceitos como "religião, magia, politeísmo, monoteísmo, mito, rito". Angelo Brelich continuou suas reformulações, confirmando religião como um produto histórico.

Em seu artigo A História das Religiões no contexto da História Cultural (2015), José Leandro Peters, pesquisador da Universidade Federal de Juiz de Fora/MG, explica que a "História Cultural das Religiões" trouxe uma nova roupagem e enriquecimento, a partir da década de 1990, dos apontamentos de Pettazzoni, Bloch, Burckhardt e Huizinga, com a aplicação de conceitos de representação, poder simbólico e apropriação de Roger Chartier. Peters promove a Escola Romana ao enfatizar a historicidade e o conceito de religião no plural e romper com o paradigma inferior/superior, erudito/popular. Para ele, o historiador cultural busca o sentido dos discursos e práticas sociais, para conhecer sua intencionalidade e interesses, uma vez que as representações do social não são neutras. É necessário historicizar o objeto, dentro do seu tempo/espaço, seus atores e seus interesses.

A professora de História Eliane Moura da Silva, da Universidade Estadual de Campinas, no artigo Entre religião, cultura e história: a escola italiana das religiões (2011), também investiga a "História Cultural das religiões" no campo conceitual, metodológico e das representações culturais, colocando a "Escola Romana de História das Religiões" no debate entre religião, história e cultura. Sua proposta é debater e refinar questões conceituais e metodológicas entre os historiadores brasileiros na sua relação com o estudo dos objetos do campo religioso. Para ela, "religião", no singular, pressupõe "cristianismo": um código cultural, universal e ocidental que a história cultural entende ter sentidos variados. O desafio da História cultural é "ligar a construção discursiva do social e a construção social do discurso na especificidade da compreensão histórica" . 8 Para a autora, as religiões são representações culturais, amplas e eficazes, que só podem ser definidas em contextos espaciais e temporais determinados e vê na "Escola Italiana de História das Religiões" uma importante contribuição para o debate conceitual e metodológico.

8 SILVA, Eliane M. Entre religião, cultura e história: a escola italiana das religiões. Revista de C. Humanas, Viçosa, v. 11. n. 2. p. 225-234, jul./dez. 2011. p. 226. 


\section{Contribuições e limites teórico-metodológicos}

Uma breve análise mostra que, em primeiro lugar, todos os autores citados tiveram uma boa receptividade com o conceito de "religião" apresentado pelos italianos, como "um produto histórico culturalmente condicionado pelo contexto e, por sua vez, capaz de condicionar o próprio contexto em que opera", no seu sentido plural e redutível à razão histórica. Religião significa diversidade e dignidade.

Torres-Londoño aponta que os historiadores da Escola Italiana das Religiões problematizaram de modo complexo o conceito de religião. ${ }^{9}$ A visão eurocêntrica que reconhece que sua origem pertence ao contexto ocidental judaico-cristão, sobretudo após a cristianização no Império Romano, sofre uma ruptura com o método historicista da experiência religiosa de Rafaelle Pettazzoni. Peters complementa que para a Escola Romana de História das Religiões, “o conceito de religião deve operar em um domínio conotado pela pluralidade dos sistemas religiosos". ${ }^{10}$ Adicionalmente, "os movimentos religiosos são redutíveis à razão histórica enquanto produtos culturais" e o historiador deve buscar os fatores condicionantes culturais da religião, investigando "a prática religiosa como uma apropriação singular que possui tanto semelhanças quanto diferenças com outras práticas religiosas, mas, nem por isso, é inferior ou superior a elas, mas simplesmente diferentes formas de religiosidade! Para Bellotti, é necessário conhecer a historicidade do conceito e que o profissional historiador aprenda a operacionalizá-lo, assumindo um critério próprio, que favoreça a religião como um fenômeno históricocultural. ${ }^{11}$ Silva reafirma a teoria e o método pettazzoniano, ao ressaltar a historicidade das religiões e dos fatos religiosos por comparação antropológica e etnológica e afirmar que as religiões são produtos culturais redutíveis à razão histórica, um conceito amplo para compreender em sua universalidade todas as formas particulares. ${ }^{12}$ Nesse sentido, a pluralidade das religiões significa uma pluralidade de histórias.

Em segundo lugar, a relação entre religião e cultura, tão essencial na abordagem italiana dos fenômenos religiosos, mereceu bastante ênfase por parte dos pesquisadores brasileiros, principalmente quanto ao tema sobre a apropriação da História das Religiões pela História Cultural. Nunes ${ }^{13}$ destaca a proximidade da Escola Italiana com a Nova

9 TORRES-LONDOÑO, F. História das Religiões. In: PASSOS, João Décio; USARSKI, Frank (Org.). Compêndio de ciência e religião. São Paulo: Paulinas/Paulus, 2013. p. 217-229.

10 PETERS, J. L. A História das Religiões no contexto da História Cultural. Faces de Clio: Revista Discente de Pós-Graduação em História da UFJF, v. 1, n. 1, jan./jun. 2015. p. 94.

11 BELLOTTI, K. K. História das Religiões: Conceitos e debates na era contemporânea. História: Questões $\mathcal{E}$ Debates, Curitiba, n. 55, p. 13-42, jul./dez. 2011.

12 SILVA, 2011.

13 NUNES, E. O. História das Religiões: delimitação de campo e escolhas metodológicas. Artigo apresentado no XI Simpósio Nacional da ABHR, Goiânia, 2009. Disponível em: <http://www.abhr.org.br/wpcontent/uploads/2013/01/art_NUNES_historia_religiões.pdf>. Acesso em: 12 jan. 2016. 
História, relacionando os estudos de Angelo Brelich, ${ }^{14}$ com Alphonse Dupont (e as categorias temporais de abordagem) e Dominique Julia (e a História Social). Bellotti também promove a comparação intercultural de Brelich, que sugere o estudo das crenças como chave teórica para entender a religião dentro de uma pluralidade de culturas. Nesse sentido, a autora reforça a necessidade de se trabalhar com a diversidade cultural e com os questionamentos trazidos pela virada linguística, Annales e Nova História, que buscam "estabelecer comparações (continuidades e descontinuidades) entre fenômenos presentes e possíveis correspondentes do passado [...] e a historicidade dos discursos, práticas, crenças e agentes religiosos, tendo em vista certas ferramentas conceituais na relação entre sociedade e indivíduos sob uma perspectiva cultural". ${ }^{15}$ Peters comenta sobre uma abordagem cultural do objeto religioso adotada atualmente pela academia e influenciada pela Nova História Cultural. Para o autor, aqueles que se preocupam com o campo religioso devem se preocupar também com o campo social. ${ }^{16}$ Silva ressalta a abordagem não-fenomenológica da escola italiana e sua base teórica para definir aquilo que em certo momento histórico-cultural uma sociedade entende por religião. De acordo com a autora, "religião" é um termo de sentido amplo e contingencial, um conceito historicamente determinado e limitado pela cultura. ${ }^{17}$

Em terceiro lugar, alguns artigos debateram o atual status da disciplina de História das Religiões no Brasil, ainda em fase de desenvolvimento e organização. O amadurecimento e institucionalização da disciplina consolidariam sua importante contribuição para o campo religioso e multiplicariam os professores, departamentos e pesquisas, contribuindo para o surgimento de novas abordagens, diálogos com outras disciplinas, teorias e metodologias. Nunes ${ }^{18}$ e Bellotti ${ }^{19}$ sugerem mais estudos para definir o objeto de estudo, a abrangência, os métodos e a proposta de formação da História das Religiões no Brasil. O primeiro a percebe como uma área interdisciplinar entre História e Ciências da Religião, que tem necessidade de definir-se para garantir e desenvolver áreas de estudo e pesquisa, além de promove o aprofundamento dos estudos teóricometodológicos para o progresso do conhecimento. Torres-Londoño afirma que a História das Religiões se encontra em um caminho ascendente desde os anos 1990, intensificando o diálogo interdisciplinar com as Ciências Humanas, a multiplicação de documentos (incluindo os registros orais e a cultura material) e a constituição de novas metodologias

14 Para quem os fenômenos religiosos precisam ser ancorados numa base teórica e definidos a partir de dado momento histórico-cultural e as crenças podem ser entendidas a partir de seu universo histórico, cultural e mental específico.

15 BELLOTTI, 2011, p. 41.

16 PETERS, 2015.

17 SILVA, 2011.

18 NUNES, E. O. A Escola Italiana de História das Religiões: a constituição de um campo historiográfico. Anais do XXVI Simpósio Nacional de História - ANPUH. São Paulo, jul. 2011. Disponível em: <http://www.snh2011.anpuh.org/resources/anais/14/1299693983_ARQUIVO_Artigo-

AEscolaItalianadeHistoriadasReligioes.pdf>. Acesso em: 15 set. 2015.

19 BELLOTTI, 2011. 
de análise. Para o autor, as religiões estão dentro da História Cultural, moldadas em seus debates e aparelhagem conceitual. ${ }^{20}$

O número de artigos disponíveis sobre a Escola Italiana de História das Religiões é ainda reduzido e reflete, mesmo comprovada a boa recepção por alguns historiadores, sua baixa difusão nos meios acadêmicos brasileiros. O professor Adone Agnolin, da Universidade de São Paulo, uma referência importante ligada à Escola Italiana por formação universitária e colaboração investigativa, é possivelmente seu melhor representante/pesquisador no Brasil, além de um importante organizador e tradutor de algumas obras para o público brasileiro (infelizmente ainda em número reduzidíssimo). Além da USP, que oferece a disciplina optativa de História das Religiões, outros pesquisadores aqui citados buscam afirmar-se no campo religioso e veem na escola italiana uma chave interpretativa de bases sólidas que condiz com a diversidade cultural brasileira e também uma alternativa para a tradicional visão positivista e marxista que ainda conduz os estudos religiosos universitários. No entanto, suas descrições sobre a Escola Italiana, ao mesmo tempo que reproduziram fielmente suas principais diretrizes, mostraram-se tímidas em explicar, aplicar e desenvolver suas metodologias ou citar estudos que as empregam. Houve muito elogio para pouca crítica. A religião, nesse sentido, não tem sido tratada devidamente pela ciência histórica brasileira, não só por não ter alcançado ainda uma autonomia disciplinar na grande maioria das universidades, como também por faltar-lhe diversidade teórico-metodológica.

A fim de contribuir para a sua divulgação, buscamos, de forma introdutória, revisar alguns pontos teóricos, metodológicos e humanistas da Escola Italiana de História das Religiões por acreditarmos ser uma importante chave de interpretação do objeto religioso nos cursos de graduação e pós-graduação e por termos verificado, a partir dos autores e artigos analisados, que foram menos explorados.

Nesse sentido, qual foi o percurso de indagação adotado para a construção do conceito de religião proposto pela Escola Italiana? Quais foram as principais obras e autores que participaram de tal revisão crítica? Como a Escola Romana se posicionou em relação às questões sobre o evolucionismo e o etnocentrismo? Nesse sentido, qual a importância do diálogo entre historiadores e antropólogos/etnólogos? Como suas metodologias se afinam e beneficiam-se reciprocamente?

Outro ponto essencial é compreender o método histórico-comparativista proposto pelos pesquisadores italianos e de sua busca pelas singularidades, contrário, assim, às categorias metatemporais, "objetivistas", holísticas e não modificáveis do conceito de religião e cultura, ao mesmo tempo que reforça a perspectiva de estudos da disciplina de História das Religiões enquanto superação das visões positivistas e marxistas tradicionais.

20 TORRES-LONDOÑO, 2013. 
$\mathrm{O}$ aspecto humanista da Escola Italiana também merece destaque. Ao investigar e questionar a hegemonia da visão eurocêntrica e cristã em parte dos estudos religiosos, ele nos desafia a repensar os valores do patrimônio cultural ocidental, na forma de uma autocrítica que analisa simultaneamente o "outro" e si mesmo, as "outras culturas" e a própria cultura, ensinando a observar e sobrepujar formas imobilizadas de interpretação e vícios analíticos nos quais predominam visões preconceituosas, intolerantes, excludentes e limitadas sobre a alteridade e a identidade de povos e culturas não-europeus.

\section{Construção do conceito "religião" pela Escola Italiana"}

A trajetória de construção conceitual dos autores que integram a Escola Italiana ocorre a partir de um diálogo crítico com uma longa tradição de pensamento e estudos sobre as religiões. A obra que melhor demonstra esse processo, e que o sistematiza, é a da Marcello Massenzio. ${ }^{22}$ Explicita-se nesse trabalho todo um esforço de seleção, classificação e avaliação criteriosa de um elenco de autores decisivos. Mas não no sentido meramente enciclopédico ou de compilação eclética de linhas de análises muitas vezes antagônicas, mas num esforço efetivamente de síntese, conforme procuramos demonstrar a seguir.

Na segunda metade do século XIX, a expansão do imperialismo europeu com a exploração principalmente das colônias africanas e asiáticas, o desenvolvimento dos grandes centros urbanos, a industrialização e a formação das classes sociais levaram ao surgimento das Ciências Sociais e, dentro delas, da Antropologia Cultural com seu especial interesse por culturas e povos não-europeus. Embora diferentes disciplinas contribuam para a História das Religiões, a Antropologia cultural tem um destaque próprio, cujo cruzamento com a História das Religiões criou um campo rico e estimulante de pesquisa: a Antropologia religiosa. Ambas reconhecem a autonomia do fato religioso, a validade relativa das categorias interpretativas e a necessidade da elaboração de novos instrumentos cognitivos de análise, contribuindo, assim, para uma revisão radical dos conceitos de religião, gerando um enriquecimento mútuo.

A obra que marcou o nascimento da etnologia foi Primitive Culture (1871), do antropólogo inglês Edward B. Tylor. Ela deriva do evolucionismo biológico de Darwin, que classifica as formas culturais por meio de leis universais determinantes e totalizantes, que seguem etapas invariáveis desde o estágio primitivo (ou embrionário, ou fase das origens) até o ápice da "civilização": a industrialização. Se, por um lado, sua teoria favorece o eurocentrismo e o etnocentrismo, por outro apresentou duas importantes rupturas epistemológicas: primeiramente, a categoria de povos "selvagens", criada pela

21 Utilizamos especialmente as obras de: MASSENZIO, 2005; AGNOLIN, 2013; e AGNOLIN, A. O debate entre História e Religião em uma breve história da História das Religiões: origens, endereço italiano e perspectivas de investigação. Projeto História, São Paulo, n. 37, p. 13-39, dez. 2008, por reunirem os principais debates e o seu refinamento no decorrer do tempo.

22 MASSENZIO, 2005. 
mente Ilustrada, foi substituída por "primitivo", um termo menos excludente que passa a ver os povos da natureza como representantes das primeiras etapas da sociedade e da cultura humanas. O segundo fator é que o evolucionismo cultural criou uma "filosofia da história" própria à etnologia, ampliando o conceito de cultura. O produto mais alto do evolucionismo cultural, do eurocentrismo e texto-chave para a cultura do século XX foi a obra Ramo de Ouro (1890), do antropólogo inglês J. G. Frazer, pesquisador de mitologia e religião comparada. Generalizador, etapista e etnocêntrico, ele trabalha com a ideia de uma evolução "natural" a partir da magia, passando pela religião (medieval cristã) e culminando na ciência moderna, o que contribuiu para incutir na mentalidade ocidental aspectos negativos da magia. Por outro lado, um aspecto positivo de seus estudos foi a análise das instituições mágicas concretas, como o "rei-mago".

Enquanto vertente resultante da reação ao evolucionismo, o funcionalismo do etnólogo polonês B. Malinowski colaborou com o debate redefinindo o estatuto de magia, religião e ciência a partir da delimitação das funções que competem a cada uma delas e afirmando sua coexistência num mesmo contexto, colocando em crise a ordem sucessiva sugerida por Tylor e Frazer. Para ele, “Todos os elementos da cultura devem ser operacionais, funcionais, ativos e eficientes [...] $\mathrm{O}$ interesse principal da antropologia funcional está nas funções das instituições, dos costumes, dos instrumentos e das ideias". ${ }^{23}$

Outro contribuinte fundamental para a construção de conceitos no âmbito religioso foi o teólogo protestante alemão Rudolf Otto. Conhecedor do debate antropológico acima descrito, sua principal obra $O$ sagrado: o irracional na ideia do divino $e$ sua relação com o racional (1917), tem reconhecimento unânime dos estudiosos. Otto funda a religião como categoria autônoma, detentora de critérios de análise específicos, e sua concepção do "sagrado" é a raiz disso: "a essência última da religião está na complexa realidade do sagrado", capaz de extrapolar a ordem humana e conduzir à dimensão da alteridade, em seu mais alto grau de intensidade. O sagrado interfere no mundo profano, sendo perceptível somente pelo sentimento: uma experiência irracional e paradoxal. Ele nega as etapas de substituição evolucionistas e sua categoria do sagrado também questiona o problema da mentalidade eurocêntrica. No entanto, deparamo-nos com a questão que diferencia a "religião" dos historiadores daquela dos "essencialistas": o sagrado é uma realidade autônoma independente ou um produto histórico-cultural?

A corrente de pensamento criada no âmbito da fenomenologia religiosa também tem no filósofo da religião e historiador holandês G. van der Leeuw e na sua obra Fenomenologia da Religião (1933) uma referência imprescindível. Com influência evidente de Rudolf Otto, ele concebe o sagrado enquanto mistério, alteridade, irracionalidade e ambivalência. Para ele, a magia é como a religião e conhece-se o fenômeno religioso pela experiência, um conceito de potência "alheia" e protesto. De forma similar, o romeno

23 MALINOWSKI apud MASSENZIO, 2005, p. 74. 
Mircea Eliade, herdeiro das ideias e teorias de Otto e van der Leeuw, reforçou de forma significativa a mesma chave de interpretação do universalismo do elemento religioso que ainda hoje atrai tanto o público leigo quanto erudito, servindo de fonte para pesquisas científicas e pseudocientíficas. Em suas considerações sobre a relação entre profano/sagrado, Eliade considera que o profano (o tempo irreal) nada mais é do que uma prerrogativa do sagrado, que existe por si só.

A Escola sociológica francesa, por meio de E. Durkheim e de sua obra As formas elementares da vida religiosa (1912), acirra o debate sobre continuidade/descontinuidade entre primitivo e moderno e as ambiguidades evolucionistas, procurando perceber o que é essencial no fenômeno religioso. No entanto, sua busca pela "origem que explica", como criticava Marc Bloch, a suposta homogeneidade das sociedades primitivas nas ideias e ações, a uniformidade da cultura e do espírito humano, sua visão etapista e a negação da diversidade são alguns pontos limitantes de sua teoria. Ao mesmo tempo, para o autor, o pensamento religioso dá origem aos primeiros sistemas de representação do mundo e tem um sentido eminentemente social. Criticou o redutivismo evolucionista (no evolucionismo cultural o afastamento predomina sobre a continuidade) e a emocionalidade e a irracionalidade de suas análises.

O debate francês foi aprimorado com os pensamentos do filósofo e sociólogo Lucien Lévi-Bruhl com sua obra A mentalidade primitiva (1922) e do antropólogo Marcel Mauss. Enquanto o primeiro apresenta um radical relativismo cultural, trabalha a partir das diferentes funções mentais (mentalidades) do homem primitivo e do homem culto ocidental e busca uma alternativa ao eurocentrismo e sua análise interpretativa, o segundo sustenta uma sistematização científica do magismo como fenômeno sociocultural. Finalmente, Claude Lévi-Strauss contribui com uma crítica à forma evolucionista de avaliar os fatos culturais e a relação entre magia e ciência. Para ele, ambos são formas de pensamento e de apreensão da realidade, com formas diferentes de conhecimento: um é a intuição do sensível (classificação que também é racional) e o outro o pensamento científico moderno.

Pettazzoni e seus seguidores foram e ainda são combatentes fervorosos das vertentes sistemática (de Tylor, Frazer e Malinowski) e essencialista-fenomenológica (de Otto, van der Leeuw e Eliade). A Escola Italiana busca superar as limitações que tais vertentes impõem para o conceito de religião, ampliando-o e tornando-o operativo no domínio da pluralidade de sistemas religiosos, tratados cientificamente com a mesma dignidade dentro de uma ideologia de reconhecimento das diversidades. Sua visão não só inseriu os povos "primitivos" no plano histórico, como também se tornou incompatível com a linha de pensamento teológica. Massenzio aponta:

Enquanto Eliade se apresenta para nós como uma chave de leitura não da dimensão religiosa completa em si, mas apenas daquele fenômeno religioso 
particular, que remete à superação da condição humana normal, ao qual se atribui o nome de misticismo, Pettazzoni, do seu lado, aspira a compreender e nos fazer compreender, mais em geral, o papel peculiar da religião dentro dos processos culturais; consequentemente, ele não privilegia o momento do sagrado, mas coloca no centro de sua reflexão a relação entre sagrado e profano. ${ }^{24}$

Adicionalmente, Pettazzoni propôs um método comparativo que privilegia as singularidades e estabelece uma relação peculiar do objeto religioso com a disciplina histórica, que:

Pressupõe a descoberta das analogias entre formações variadas como fase preliminar que permite, depois, definir com rigor a especificidade de cada fenômeno, de cada contexto, cujo objetivo posterior é a reconstrução do processo de formação de um dado produto religioso ou de uma dada religião em seu conjunto. 25

O afinamento dos instrumentos teóricos e metodológicos prosseguiu com o "novo humanismo" de Ernesto de Martino e Angelo Brelich, que reforçaram a abertura à alteridade extraocidental e a origem das religiões como algo culturalmente produzido. Brelich se mostra especialmente interessado em recuperar o contexto histórico no qual, concretamente, tomaram forma determinados fenômenos religiosos e o centro do interesse de E. de Martino é o problema da hierogênese, isto é, do nascimento e construção do sagrado enquanto tal, em resposta a determinadas necessidades relacionadas com a precariedade da existência humana no mundo.

Tanto para E. de Martino quanto para Mircea Eliade, recorrer ao sagrado tem a função de salvação e o nexo entre religião e crise tem importância central. No entanto, para Eliade, o porvir tem um caráter negativo, por isso a necessidade de fugir para o sagrado. Já De Martino evita generalizações e debate sobre os "momentos críticos do porvir", isto é, momentos específicos de um contexto angustiante econômico e social, no qual a existência coletiva se encontra ameaçada e à qual se faz necessário dar um sentido cultural (por exemplo, o mito cristão da Semana Santa). Se Eliade supervaloriza o sagrado, De Martino o subvaloriza. Para este, a realização humana está dentro do mundo profano. Dessa forma, sua preocupação com a “des-historificação" religiosa (a negação ou ocultação da História) se mostra legítima e digna de debate. Ele complementa que:

O não-reconhecimento da dinâmica mágico-religiosa se liga a precisas razões históricas: à polêmica cristã contra o paganismo, à polêmica protestante contra o ritualismo católico, à ideia de uma magia natural no

24 MASSENZIO, 2005, p. 156.

25 MASSENZIO, 2005, p. 150. 
Renascimento e, por fim, à obstinação com a qual o pensamento moderno continua a chamar de religião a sua própria persuasão humanista. ${ }^{26}$

Conforme De Martino, para se aproximar do outro cultural, faz-se necessário se afastar do pensamento eurocêntrico, sem deixar, no entanto, de vê-lo como alteridade, como uma alternativa de interpretação, conhecendo, assim, suas formas e limites, conhecendo "outras" civilizações a partir de um método qualitativo (com novas categorias cognitivas) e do conhecimento de si mesmo para entender os "outros". Adicionalmente, a superação dos limites do etnocentrismo passa por uma reavaliação ocidental de seu patrimônio cultural.

Angelo Brelich reflete sobre as características do objeto da história das religiões e sua maneira eurocêntrica de ser feita. Por ser um conceito exclusivamente ocidental, este tipo de "religião" não alcança as particularidades dos fenômenos religiosos, uma vez que cientificamente não poderia corresponder a uma essência universal. Ele trabalha com os elementos religiosos (mitos, ritos, seres sobre-humanos) por meio de um método comparativo e de categorizações dos fatos para reafirmar a pluralidade dos fenômenos ao mesmo tempo em que cria uma chave de interpretação de longo alcance. Seu comparativismo intercultural "fornece o quadro das convergências, a partir do qual tornase possível entender os fatores que caracterizam os contextos histórico-culturais particulares", método iniciado por Pettazzoni e aperfeiçoado por Brelich, para quem a primeira manifestação religiosa ocorreu na pré-história.

Assim, a teoria e metodologia desenvolvidas por esses três grandes autores da Escola Italiana não só demonstram um grande fôlego intelectual, mas também um questionamento extenso e profundo que criou um conceito preciso de "religião" e uma disciplina singular, a História das Religiões, necessária para a especificidade de análise do objeto religioso.

A partir dessas reflexões algumas problemáticas emergem no centro do projeto de se elaborar uma estratégia de abordagem, das crenças e práticas religiosas, que seja genuinamente uma abordagem histórica. Trata-se de propor uma solução coerente para o duplo problema colocado no processo de apreensão do objeto religioso. Problemas claramente colocados por Dominique Julia num texto clássico de 1974. Por um lado a religião torna-se um sintoma, "sinais de uma coisa diferente daquela que pretende dizer", 27 ou seja, meio para se compreender a sociedade e a cultura da qual emerge. Se os membros de uma determinada sociedade entendem a religião como fundamento último da ordem social, caberia ao estudioso procurar entender que tipo de sociedade reivindica para sí um determinado grau de amarração religiosa. Mas a questão imediata que se coloca diz

26 MARTINO apud MASSENZIO, 2005, p. 176.

27 JULIA, Dominique. História religiosa. In: GOFF, Jacques Lê; NORA, Pierre (Org.). História: novas abordagens. Rio de Janeiro: Francisco Alves, 1995. p. 108. 
respeito à natureza dessa mesma religião e porque na sua lógica própria e na sua autonomia enquanto dimensão específica da realidade, ela cumpre o papel que lhe é definido. Em outros termos, trata-se de enfrentar o problema do anacronismo e do etnocentrismo no estudo das religiões. Pois a estratégia de se considerar as manifestações tidas como religiosas no seu contexto histórico específico exige todo um esforço de historicização do conceito de religião. A questão é como estudar a religião de uma sociedade e de uma cultura que não possui o conceito de religião? Nos termos de Dominique Julia, a questão é: “como compreender com as nossas categorias mentais e nossos conceitos de hoje o que é fundamentalmente diferente, o que é fundamentalmente outro ?". 28 Uma alteridade, um outro que existe num espaço e num tempo diferente.

A proposta de A.Brelich, resumida por Massenzio, caminha no sentido de partir de um cenário marcado por algumas exigências e condições teóricas e metodológicas. Entre elas, podemos citar, a necessidade de se negar a absolutização acrítica de um modelo particular de religião; a busca da formação de uma consciência histórico-religiosas; a busca de uma chave interpretativa que abra o acesso a todos os sistemas religiosos, operando no domínio da pluraridade; a busca de um fundamento para a disciplina "história das religiões", capaz de superar a mera compilação enciclopédica das crenças; construir um conceito que pense a religião em termos de suas qualidades, ou seja, trata-se de uma realidade viva e dinâmica que nasce de determinados contextos históricos e mantém com esse contexto uma relação de reciprocidade, elemento condicionado e condicionante; o reconhecimento positivo da diversidade religiosa e a necessidade de abordá-los de maneira comparativa, buscando suas distinções e especificidades, bem como buscando reconstituir seu processo específico de formação.

Mas além de estabelecer qualidades ao fenômeno religioso, o conceito deve ainda buscar estabelecer alguns pontos fixos que aponte para seus conteúdos mais gerais e permanentes. A questão é como distiguir o objeto cultural religioso de outros objetos culturais. O primeiro passo é romper com o pressuposto de que o conceitos de religião, tal como foi elaborado pela civilização ocidental e sua formação religiosa específica, contenha em si a essência universal do fenômeno. O segundo passo é identificar e isolar teoricamente elementos comuns do fenômeno, que de conta de sua universalidade desse objeto, e ao mesmo tempo precisar as distintas formas possíveis de combinação desses elementos, que de conta de suas especificidades.

Em síntese, os pontos fixos sobre os quais se pode edificar uma noção de religião, que possa emergir dos dados históricos e que resulte aplicável à totalidade das culturas, remetem-se a três elementos substanciais,

28 JULIA, 1995, p. 109. 
solidamente entreligados: o controle do não-humano, a atribuição recíproca de sentido e a 'promoção' da atividade humana, por último considerada. ${ }^{29}$

O terceiro passo concentra-se na definição do método, entendido aqui como a postura e a perspectiva que o sujeito do conhecimento deve adotar diante de seu objeto de pesquisa. Nesse caso, o método indicado é o histórico-comparativo que tem com fundamento a defesa da unicidade da história humana cuja estrutura e dinâmica não se dá de forma evolutiva mas a partir de uma diversidade de culturas que se constituem num processo de trocas e assimilações, mas também a partir de "um amplo movimento dialético capaz de tornar reciprocamente funcionais o geral e o particular, o próprio e o outro". 30

Fica claro o desafio metodológico presente na proposta. Como num mesmo movimento de apreensão deve-se articular uma abordagem genética do objeto religioso, levando em conta sua formação e transfomação nas coordenadas do tempo, e uma abordagem mais estrutural, que reconstitua as diferentes articulações que a dimensão religiosa mantém com outros setores da realidade, como a dimensão econômica, social, política e cultural.

Mas é justamente nesse ponto que emerge uma questão crucial, não explicitada claramente nas reflexões teóricas dos autores aqui comentados. Fala-se com insistência na necessidade de indicar um peso explicativo para os contextos históricos, mas não fica evidente o modo como os autores entendem o funcionamento específico desses mesmo contexto. Em outros termos, falta uma definição do conceito de totalidade.

\section{Perspectivas de estudos}

Os historiadores brasileiros que se interessam pela Escola Italiana se deparam primeiramente com a dificuldade de encontrar as obras de seus principais expoentes traduzidas para a língua portuguesa. Dessa forma, o estudo da língua italiana é fundamental para o aprofundamento dos estudos. Da mesma forma, as universidades brasileiras, em sua grande maioria, não oferecem na grade curricular a disciplina de História das Religiões, seja na forma obrigatória ou optativa, afastando o estudante/pesquisador de suas teorias e metodologias específicas, o que por um ângulo poderia justificar a ausência de uma base para abordar o objeto religioso. Adicionalmente, como parte dos objetivos deste projeto, listamos algumas questões que podem sugerir novas direções para os seus estudos:

1. Como a chave de interpretação da Escola Italiana se aplica ao próprio cristianismo ocidental?

29 MASSENZIO, 2005, p. 182-183.

30 MASSENZIO, 2005, p. 184. 
2. Como a teoria e metodologia da Escola se inserem no debate sobre secularização/reavivamento religioso?

3. Verifica-se, atualmente, uma forte penetração da esfera religiosa em todos as esferas da existência e o aparecimento das "religiões públicas". Pastores evangélicos realizam cultos dentro de instituições públicas e os direitos constitucionais são inferiorizados pelos direitos religiosos. Como a Escola Italiana interpretaria tal movimento?

4. Alguns autores defendem que há uma forte expansão da religião na forma de uma moral profana que prega o bem viver, a saúde, formas de empreendedorismo econômico, ou como salvar seu casamento, como educar os filhos, etc. Como a Escola enxerga tal prolongamento?

5. A disciplina de História das Religiões foi criada na USP em 2007. Como tem sido sua receptividade pelos estudantes da graduação e pós-graduação e seu desenvolvimento na comunicação com outros departamentos e disciplinas?

6. Como deveria ser a formação de um historiador das religiões brasileiro por viver em um país periférico e, nesse sentido, extraocidental, ao mesmo tempo bastante diverso culturalmente?

7. Quais são os limites teóricos e metodológicos da Escola Italiana? E os novos horizontes de pesquisa? Quais são os cuidados para não se incorrer no anacronismo, uma vez que seus estudos enfatizam o outro no espaço e não no tempo?

\section{Referências}

AGNOLIN, A. História das Religiões: perspectiva histórico-comparativa. São Paulo: Paulinas, 2013.

. O debate entre História e Religião em uma breve história da História das Religiões: origens, endereço italiano e perspectivas de investigação. Projeto História, São Paulo, n. 37, p. 13-39, dez. 2008.

BELLOTTI, K. K. História das Religiões: Conceitos e debates na era contemporânea. História: Questões E Debates, Curitiba, n. 55, p. 13-42, jul./dez. 2011.

BUARQUE, V. A. C. A especificidade do religioso: um diálogo entre historiografia e teologia. Projeto História, São Paulo, n. 37, p. 53-64, dez. 2008.

CHAUÍ, M. A experiência do sagrado e a instituição da religião. In: CHAUÍ, M. Convite à filosofia. São Paulo: Ática, 2010.

FILORAMO, G. Monoteísmos e dualismos: as religiões de salvação. São Paulo: Hedra, 2005.

GAARDER, J.; HELLERN, V.; NOTAKER, H. O livro das Religiões. São Paulo: Companhia das Letras, 2000. 
JULIA, Dominique. História religiosa. In: GOFF, Jacques Lê; NORA, Pierre (Org.). História: novas abordagens. Rio de Janeiro: Francisco Alves, 1995. p. 106-131.

LANTERNARI, V. As religiões dos oprimidos. São Paulo: Perspectiva, 1974.

MASSENZIO, M. A história das religiões na cultura moderna. São Paulo: Hedra, 2005.

NUNES, E. O. A Escola Italiana de História das Religiões: a constituição de um campo historiográfico. Anais do XXVI Simpósio Nacional de História - ANPUH. São Paulo, jul. 2011. Disponível em:

<http://www.snh2011.anpuh.org/resources/anais/14/1299693983_ARQUIVO_ArtigoAEscolaItalianadeHistoriadasReligioes.pdf>. Acesso em: 15 set. 2015.

. História das Religiões: delimitação de campo e escolhas metodológicas. Artigo apresentado no XI Simpósio Nacional da ABHR, Goiânia, 2009. Disponível em:

<http://www.abhr.org.br/wp-

content/uploads/2013/01/art_NUNES_historia_religiões.pdf>. Acesso em: 12 jan. 2016.

. Teoria e Metodologia em História das Religiões no Brasil: o estado da arte.

História: Questões \& Debates, Curitiba, n. 55, p. 43-58, jul./dez. 2011.

OLIVEIRA, G. P. A Escola Italiana de História das Religiões de Rafaelle Pettazzoni e seus diálogos e confrontos. In: MATA, Sérgio Ricardo; MOLLO, Helena Miranda; VARELLA, Flávia Florentino (Orgs.). Caderno de resumos $\mathcal{E}$ Anais do $2^{\circ}$. Seminário Nacional de História da Historiografia. A dinâmica do historicismo: tradições historiográficas modernas. Ouro Preto: EdUFOP, 2008. Disponível em:

<http://www.seminariodehistoria.ufop.br/seminariodehistoria2008/t/gisele.pdf>. Acesso em: 03 mar. 2016.

PETERS, J. L. A História das Religiões no contexto da História Cultural. Faces de Clio: Revista Discente de Pós-Graduação em História da UFJF, v. 1, n. 1, jan./jun. 2015.

REVERI, M. Índia e Extremo Oriente: a via da libertação e da imortalidade. São Paulo: Hedra, 2005.

SCARPI, P. Politeísmos: As religiões do mundo antigo. São Paulo: Hedra, 2004.

SILVA, Eliane M. Entre religião, cultura e história: a escola italiana das religiões. Revista de C. Humanas, Viçosa, v. 11. n. 2. p. 225-234, jul./dez. 2011.

TORRES-LONDOÑO, F. História das Religiões. In: PASSOS, João Décio; USARSKI, Frank (Org.). Compêndio de ciência e religião. São Paulo: Paulinas/Paulus, 2013. p. 217-229. 